\title{
DO SERTÃO PARA OS BOULEVARDS: S. BERNARDO, DE GRACILIANO RAMOS ${ }^{1}$
}

Ana Maria Bicalho ${ }^{2}$

RESUMO: O presente trabalho se propõe a analisar as estratégias de importação responsáveis pela escolha de traduzir para o francês o romance $S$. Bernardo, de Graciliano Ramos, estabelecendo o lugar que ocupava nos sistemas literários brasileiro e francês, no momento em que foi escrito e traduzido. O trabalho destaca a perda da estatura canônica de Graciliano Ramos, quando do deslocamento de sua obra para o sistema literário francês e inclui, ainda, reflexões sobre o hiato decorrido entre a publicação e a tradução para a língua francesa do referido romance, as estratégias de tradução e de importação responsáveis pela escolha dessa obra, identificando as soluções encontradas pela tradutora francesa para a recriação de elementos linguístico-culturais específicos do sertão e da zona da mata de Alagoas que passam a se inscrever em outro sistema linguístico-cultural. A análise traz à tona as relações entre tradução, contexto cultural e sistema literário, demonstrando que o processo de recriação é afetado não apenas pela forma como os textos são traduzidos, mas também pelo momento em que determinada cultura solicita a tradução.

PALAVRAS-CHAVE: Graciliano Ramos, Tradução, Polissistema, Cultura.

ABSTRACT: This paper aims to analyze the import strategies which motivated the choice of translating into French Graciliano Ramos' São Bernardo, as well as to determine the place this novel occupied in the Brazilian and French literary systems at the time when it was written and translated. The paper underlines that Graciliano Ramos lost his canonical status when his work was shifted to the French literary system. Moreover, it includes reflections on the gap between the publication in Brazil and the translation into French of the novel, as well as the translation and import strategies which motivated the choice of such work. The paper also identifies the solutions found by the French translator to re-create linguistic and cultural elements that are typical to the sertão (backlands) and the zona da mata (forest zone) of the Alagoas state, which then became part of another linguistic and cultural system. The analysis brings up the relationships between translation, cultural context and literary system, demonstrating that the process of re-creation is influenced not only by the form in which the texts are translated, but also by the moment in which a given culture calls for a translation.

KEY WORDS: Graciliano Ramos, Translation, Polisystems, Culture.

\footnotetext{
${ }^{1}$ Versões preliminares deste texto foram apresentadas em seminários estudantis de pesquisa na Universidade Federal da Bahia e compõem minha tese de doutorado defendida em agosto de 2010 junto ao Programa de Pós-Graduação em Letras e Linguística da UFBA.

${ }^{2}$ BICALHO, Ana Maria Bicalho. Doutora em Letras e Linguística (UFBA) e professora adjunta do Departamento de Letras Românicas da Universidade Federal da Bahia. E-mail: bicalhoana@hotmail.com
} 


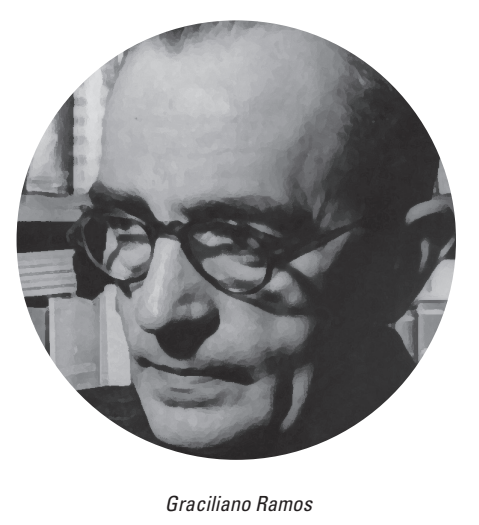

\section{INTRODUÇÃO}

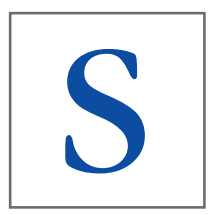

abemos que os choques entre culturas podem ser abrandados a partir do entendimento dos costumes, das filosofias e também da língua do Outro. Esse contato entre povos diferentes se faz presente também através da tradução. Esse trabalho fronteiriço da tradução exige, segundo Bhabha (1998, p. 27), "um encontro com o 'novo' que não seja parte do continum de passado e presente. Ele cria uma ideia de novo como ato insurgente da tradução cultural".

Uma vez desfeito o sonho pré-babélico de unidade e de completude, traduzir passa a ser, também, um trabalho que envolve, além de línguas e cultura, o poder de apoderar-se e adaptar o significado do Outro. A tradução, sob o viés cultural, atenta para a possibilidade do conhecimento do "diferente", suscitando algumas reflexões:

Se não permito que o Outro me penetre e faça seus "estragos", questionando o que me é próprio, não permito que a tradução cultural se realize de maneira consequente, pois a tentativa de reduzir outra cultura aos padrões existentes na minha é imposição. É exercer o poder de mando. A tradução cultural pede uma relação erótica (entender o Outro não como ameaça à própria existência, mas como desafio e promessa) em que certamente os sujeitos saem diferentes no final do processo, transformados. Permanecem sendo eles, mas penetrados pelo Outro (BORGES e NERCOLINI, 2003).

A prática tradutória surge, pois, como uma poderosa ferramenta de impulso para que as culturas ultrapassem suas fronteiras geográficas e, sobretudo, linguísticas. Torna-se uma ponte que une diferentes visões de mundo e gera distintas interpretações de objetos e acontecimentos. Como bem observado por Elizabeth Ramos (1999), quando não se tem a possibilidade de conhecer novas culturas ou quando não se fala uma língua estrangeira, é a tradução que nos leva a conhecer o Outro e a compreender as diferenças entre as sociedades e seus costumes. 
A tradução concede, portanto, ao leitor "a lente que faculta, à miopia do monolíngue, enxergar o mundo, vasto mundo que se estende para além de suas limitações linguísticas” (PAES, 2008, p. 110). E não podemos esperar ou exigir que os textos traduzidos digam a mesma coisa que os textos "originais". Isso nunca será possível, pois:

[...] sempre ocorre algo de novo ${ }^{3}$. Inclusive, e, sobretudo, nas boas traduções. Há transformações que correspondem, de um lado, à transmissão em um contexto cultural, político e ideológico diferente, a uma tradição diferente e que fazem com que "o mesmo texto" - não existe um mesmo texto, inclusive o original não é idêntico a si mesmo -, numa mesma cultura tenha efeitos diferentes [...] (DERRIDA, 1999b, p. 62-63).

É sobre a figura do tradutor que gostaríamos de iniciar esse breve relato de pesquisa analisando a tradução do romance $S$. Bernardo, de Graciliano Ramos para o francês e apontando as escolhas feitas pela tradutora Geneviève Leibrich ao traduzir as expressões idiomáticas e o vocabulário típico de uma parte da região nordeste.

Em um primeiro momento analisaremos o contexto histórico-cultural em que o romance foi traduzido, buscando compreender os fatores que propiciaram a entrada dessa obra na França, depois de decorrido longo tempo de sua publicação no Brasil. Em seguida, passaremos à análise da tradução propriamente $\operatorname{dita}^{4}$.

\section{A RECEPÇÃO DA LITERATURA BRASILEIRA NA FRANÇA}

A tradução oferece-nos a possibilidade de dialogar com outras culturas, de nos aproximarmos do Outro, de conhecer sua cultura e, ao mesmo tempo, atentarmos para a nossa. De fato, mesmo a decisão de publicação e a recepção de uma obra literária ou de um autor estrangeiro respondem às necessidades internas e/ou expectativas do polissistema ${ }^{5}$ receptor literário, artístico, histórico e político da época, assim como, aos pressupostos e clichês difundidos sobre o país de origem.

Prova disso é a tradução de S. Bernardo. Considerado um dos romances mais densos da literatura brasileira, S. Bernardo foi traduzido para o alemão, espanhol, finlandês, francês, húngaro, holandês, inglês e italiano. Foi, também, traduzido para o cinema em 1971, com direção de Leon

\footnotetext{
${ }^{3}$ Esse "algo novo" tornaria a tradução também um texto "original".

${ }^{4}$ Diante da grande extensão do corpus, concentraremos nossa análise, neste artigo, no léxico da fauna e da flora do sertão alagoano, e nas expressões idiomáticas, frequentemente utilizadas pelo escritor alagoano.

${ }^{5}$ Termo utilizado por Itamar Even Zohar (1990) em sua Teoria dos Polissistemas que se propõe a analisar as condições particulares em que uma obra literária é produzida, observando como o sistema de origem irá atuar em outro sistema receptor. Diferentemente dos modelos anteriores, o sistema desenvolvido por esse autor não se restringe ao texto propriamente dito, nem os analisa isoladamente, desconsiderando seu contexto histórico-cultural. Essa teoria serviu de aporte teórico para a análise do contexto em que as traduções são solicitadas, pois acreditamos que todo texto traduzido faz parte de um sistema literário nacional e é regido por leis internas e externas ao seu polissistema; e que existem “jogos de poder” que governam o que será ou não publicado ou traduzido, tornando-se necessário examinar o momento e o contexto em que um texto é escrito e/ou traduzido.
} 
Hirszman ${ }^{6}$. As traduções obtiveram grande sucesso e repercussão crítica em diversos países, sobretudo na Alemanha, onde, apenas em 1960, o romance teve cinco reedições, valendo ressaltar que a primeira tiragem foi de sete mil exemplares e que o intervalo entre a primeira e a segunda edição foi de apenas quinze dias 7 . S. Bernardo foi também bem aceito na Grã-Bretanha, tendo sido responsável pela entrada dos outros romances de Graciliano Ramos neste polissistema.

Diferentemente do que aconteceu na Alemanha e na Grã-Bretanha, S. Bernardo, o romance, não foi traduzido na França, sob a alegação de que a obra não parecia importante o suficiente para que sua tradução fosse justificada. Em carta das Éditions Albin Michel a D. Heloísa Ramos, percebemos que a editora cogitou uma tradução em 1961, antes mesmo da publicação de Vidas $S_{\ell-}$ cas, romance mais representativo de Graciliano Ramos no polissistema francês. Nessa carta, a editora exalta a qualidade da obra e encerra recusando a tradução, pois, de acordo com os responsáveis,

[...] há um problema e uma situação que parecem especificamente brasileiros e sem um verdadeiro alcance universal; a obra, merecendo a devida atenção, não parece tão importante para que a sua tradução seja aconselhada $[. . .]^{8}$ (rapport - Éditions Albin Michel, 1961).

Mesmo elogiando a obra, o editor acrescenta que, apesar da possibilidade de inclusão do romance no programa da coleção de literatura estrangeira, "o programa está tão sobrecarregado que fomos levados a recusar esse empreendimento, além disso, as previsões de venda pareciam bem incertas" $"$

Fica claro, aqui, que o mesmo conteúdo cultural foi interpretado de diferentes maneiras, em diferentes países e épocas, devido a circunstâncias particulares. Retomamos, aqui, a teoria dos polissistema para ratificar a importância do contexto sócio-histórico e cultural na aceitação/solicitação de uma tradução em determinada cultura: "as traduções não devem ser analisadas isoladamente, mas dentro de um sistema em que existem fatores que regem a seleção desses textos" (EVEN-ZOHAR, 1979, p. 125). Lembramos que, no período de 1959 a 1969, Jorge Amado, o autor brasileiro que mais agradou aos franceses, deixou de ser traduzido, o que nos leva a supor que os acontecimentos históricos da época não favoreceram a tradução desses dois escritores, ou dos escritores brasileiros de forma geral.

Aplicando-se a teoria dos polissistemas ao caso da relação entre a literatura brasileira e os polissistemas hegemônicos de língua francesa, observamos uma posição periférica do sistema literário brasileiro em relação à literatura produzida na França. Se tomarmos como exemplo o ano de 1994, podemos verificar que as editoras francesas adquiriram os direitos de 1.508 títulos sen-

\footnotetext{
${ }^{6}$ SÃO BERNARDO. Direção: Leon Hirszman. Embrafilme, Mapafilme e Sagafilmes, 1971. (103 min.).

${ }^{7}$ Informação retirada de diversos jornais da época que compõem o acervo de Graciliano Ramos no Instituto de Estudos Brasileiros (IEB).

${ }^{8}$ Minha tradução de: «[...] il y a là un problème et une situation qui paraissent spécifiquement brésiliens et sans vraie portée universelle; l'oeuvre, tout en méritant l'attention, ne semble quand même pas assez importante pour que sa traduction puisse être conseillée.» (rapport - Éditions Albin Michel, 1961).

${ }^{9}$ "[...] ce programe est si chargé que nous avons été amenés à renoncer à cette entreprise, les prévisions de vente paraissant d'autre part assez. incertaines». (Ibid).
} 
do 1.347 de língua inglesa; 89 de língua alemã; 58 de língua espanhola e, por último, 14 de língua portuguesa. Quando comparado às outras línguas, esse número torna-se bastante inexpressivo. Vale ainda ressaltar que não se trata apenas de romances brasileiros, mas de romances em língua portuguesa traduzidos na França, incluídos aqui os romances portugueses e dos países da África lusófona. Durante todo o ano de 1994 foram traduzidos apenas quatro romances brasileiros (TORRES, 2004).

Como observou Torres (2004), foi apenas nos anos de 69-70 que o Brasil começou a figurar, com frequência, nos jornais franceses. Com o retorno de Jorge Amado à França em 1965, após um exílio de seis anos imposto pelo governo francês, o boom da Literatura Latino-Americana no início da década de 60 e toda a influência da música e do cinema brasileiros, o Brasil começou a se destacar no polissistema francês. De fato, a presença do cinema e da música do Brasil pode ter favorecido a descoberta do país e despertado o interesse por sua literatura. Através do cinema, a França descobriu um outro Brasil, um país em preto e branco, da miséria, da vida dura, das diferenças sociais, das agruras do nordestino, com os filmes de Glauber Rocha, Ruy Guerra e Nelson Pereira dos Santos, amplamente divulgados nos circuitos dos cineclubes e considerados revelações no festival de Cannes. A partir desse período, outros escritores canônicos brasileiros, a exemplo de Graciliano Ramos, começaram (ou recomeçaram) a ser traduzidos na França.

Retomando o caso de $S$. Bernardo, apesar de a sua tradução não ter sido acolhida nos anos 60, no início dos anos 80, mesmo sem grandes expectativas de vendas, as editoras Gallimard solicitam a D. Heloísa Ramos autorização para traduzir S. Bernardo. O romance foi publicado em 1986, período no qual se percebe um esforço por parte das editoras francesas de (re)tradução dos clássicos da nossa literatura. Salientamos que Vidas Secas já havia sido traduzido (1964), e a obra de Graciliano já havia rendido três filmes: Vidas Secas (1963), S. Bernardo (1971) e Memórias do Cárcere (1984), que já haviam sido lançados, premiados e aclamados pela crítica. Tal fato comprova não apenas que a tradução responde às necessidades do polissistema receptor, que se modificam no tempo e no espaço, mas também que existe uma interferência entre os diferentes polissistemas na aceitação de determinado autor ou literatura ${ }^{10}$.

\title{
TRADUZINDO GRACILIANO RAMOS
}

\author{
Em carta a D. Heloísa Ramos, Graciliano escreve:
}

[...] S. Bernardo está pronto, mas foi escrito quase todo em português, como você viu. Agora está sendo traduzido para o brasileiro, um brasileiro encrencado, muito diferente desse que aparece nos livros da gente da cidade, um brasileiro de matuto, com uma quantidade enorme de expressões inéditas, belezas que eu

\footnotetext{
${ }^{10}$ Ainda hoje Graciliano Ramos é pouco conhecido na França. Seus livros venderam poucos exemplares, mesmo que dois deles - a S. Bernardo e Angústia - façam parte da "Coleção de Obras Representativas" da UNESCO. Seu primeiro livro traduzido foi Infância, em 1956, reeditado em 1991. Quase dez anos depois, Marie-Claude Roussel traduz Vidas Secas, obra reeditada em 1989. Após um período de vinte e dois anos foi traduzido S. Bernardo (1986) e, dois anos depois, Memórias do Cárcere. Angústia só foi traduzido para o francês em 1992. Há ainda, em 1998, a tradução de Insônia. Todos esses livros foram traduzidos pela Gallimard, como parte da Collection du monde entier, à exceção das primeiras edições de Enfance e Sécheresse que pertenciam à Collection Croix Sud.
} 
mesmo nem suspeitava que existissem. Além do que eu conhecia, andei a procurar muitas locuções que vou passando para o papel. O velho Sebastião, Otávio, Chico e Zé Leite me servem de dicionários. O resultado é que a coisa tem períodos absolutamente incompreensíveis para a gente letrada do asfalto e dos cafés. Sendo publicada, servirá muito para a formação, ou antes, para a fixação, da língua nacional. Quem sabe se daqui a trezentos anos eu não serei um clássico? Os idiotas que estudarem gramática lerão S. Bernardo, cochilando e procurarão nos monólogos de seu Paulo Honório exemplos de boa linguagem (RAMOS, 1992, p. 131).

Traduzir certos aspectos de uma cultura em outra não consiste jamais no exercício de meras substituições, pelo contrário, a imagem que cada um tem de sua cultura e da cultura do Outro afeta sua interpretação, mesmo a tradução de um elemento aparentemente "simples" está carregado de imagens distintas. Por exemplo, a palavra sertão, que em francês poderia ser traduzida por sertaon ou permanecer em português, uma vez que os franceses estão habituados a ouvi-la e remetê-la imediatamente a uma região do Brasil. Mas será que essa palavra, traduzida ao pé-da-letra, significa a mesma coisa para um retirante, para nós brasileiros não habitantes dessa região e para um francês? Obviamente não, a imagem do sertão e sua carga semântica não serão as mesmas uma vez que, com diferentes vivências, não poderíamos interpretá-la da mesma forma. Ao analisarmos uma tradução, deparamo-nos com o olhar do Outro sobre nós, ou melhor, com aquilo que compreendemos ser o olhar do Outro. Olhar, moldado por sua cultura e singularidade, o que torna sua tradução um texto único.

Traduzir o "Velho Graça" é ainda mais difícil, se levarmos em consideração que as expressões e termos por ele utilizados são típicos de sua cultura e de sua forma de escrever. Segundo o próprio autor, essa dificuldade advém das diferenças linguísticas e culturais existentes entre a linguagem do matuto e a dos homens letrados. Se para um homem das letras seria difícil compreendê-lo, essa dificuldade torna-se ainda mais acentuada, quando pensamos na tradução dos romances de Graciliano Ramos para o francês. Encontramos a confirmação desse fato em algumas de suas cartas a seus tradutores argentinos, Benjamín de Garay e Raúl Navarro, nas quais ele mesmo se dispõe, insistentemente, a explicar certas expressões regionais presentes em S. Bernardo:

S. Bernardo tem centenas de locuções regionais, coisas do Nordeste que não figuram na língua dos livros. Caso o senhor ache necessário, pode mandar-me uma lista de palavras e frases desconhecidas, que eu lhe enviarei as formas correspondentes neste horrível português que infelizmente ainda usamos (MAIA, 2008, p. 23).

[...] estou às suas ordens para qualquer consulta que deseje fazer-me a respeito da significação de certas expressões regionais. Pode, querendo mandar-me uma lista das dificuldades que encontrar. Eu já tinha dito ao Garay que isto me parecia indispensável a quem quisesse realizar um trabalho honesto (MAIA, 2008, p. 125). 
Sabemos que, em Graciliano Ramos, a própria língua mostra-se, claramente, um elemento cultural. Destaca-se, em suas obras, a utilização de um vocabulário típico das Alagoas, marcado pelo uso de expressões e termos que dificultam a compreensão dos leitores que estão fora desse contexto, aqui incluídos os tradutores. Seus romances envolvem a seca, a caatinga, o drama dos retirantes, a solidão, a exclusão, a cidade, através de acentuada capacidade de síntese; isto é, de dizer o essencial em poucas palavras. Reescrevia seus textos várias vezes com o intuito de retirar deles tudo o que fosse desnecessário:

Deve-se escrever da mesma maneira como as lavadeiras lá de Alagoas fazem seu ofício. Elas começam com uma primeira lavada, molham a roupa suja na beira da lagoa ou do riacho, torcem o pano, molham-no novamente, voltam a torcer. Colocam o anil, ensaboam e torcem uma, duas vezes. Depois enxáguam, dão mais uma molhada, agora jogando a água com a mão. Batem o pano na laje ou na pedra limpa, e dão mais uma torcida e mais outra, torcem até não pingar do pano uma só gota. Somente depois de feito tudo isso é que elas dependuram a roupa lavada na corda ou no varal, para secar. Pois quem se mete a escrever devia fazer a mesma coisa. A palavra não foi feita para enfeitar, brilhar como ouro falso; a palavra foi feita para dizer ${ }^{11}$.

Graciliano Ramos busca sempre a concisão, a palavra certa. Elimina o adjetivo. Foge do "português que aparece nos livros da gente da cidade", da linguagem erudita e enfeitada. Utiliza expressões populares sertanejas e vocabulário típico da região, usados por personagens que reconstroem angústias, dúvidas, sonho e conflitos próprios do humano. Os seus romances apresentam regionalismos em quase todos os parágrafos, e a falta de correspondência entre "práticas e culturas diferentes" causa extrema dificuldade à tarefa do tradutor francês.

Antes de nos debruçarmos sobre a tradução de $S$. Bernardo para o francês, devemos salientar que, no processo de (re)criação não podemos esperar que a tradução reproduza a totalidade do texto fonte, que tenha o mesmo estilo, fluência e naturalidade. Aliás, afirmações desse tipo já não fazem mais sentido atualmente, pois todo "original" depende do tradutor para a sua sobrevivência em outras línguas, em outras culturas, e qualquer reflexão sobre tradução deveria partir sempre do princípio de que ela é necessária, pois permite ao leitor monolíngue o acesso, em nosso caso específico, a uma obra literária escrita em outro idioma. Além disso, o significado das palavras não é fixo, surgindo, como bem observou Hall (2006, p. 40) "nas relações de similaridade e diferença que as palavras têm com outras palavras no interior do código da língua".

Como vimos, o leitor francês só conhece a tradução de S. Bernardo em 1986, vinte e dois anos após a publicação de Sécheresse, período em que a França começa a publicar traduções e retraduções de clássicos da nossa literatura. $S$. Bernardo teve seu título preservado em francês por Geneviève Leibrich. Da tradução francesa do romance não constam prefácio, notas introdutórias ou glossário com o intuito de fornecer ao leitor informações que poderiam ser consideradas indispensáveis. A única estratégia utilizada pela tradutora para explicar algumas palavras estrangeiras foi

\footnotetext{
${ }^{11}$ Graciliano Ramos, em entrevista concedida em 1948.
} 
o uso de notas de rodapé, três no total.

No romance, Paulo Honório, o narrador, sente a necessidade de escrever e conta com a ajuda de alguns amigos para desenvolver essa empreitada. $\mathrm{O}$ trabalho não vai adiante devido à forma como pretendiam escrevê-lo. A linguagem simples e direta é fundamental, como já visto anteriormente, para a caracterização do personagem/narrador e para determinar a posição do escritor Graciliano Ramos. O léxico contido em S. Bernardo é representativo da variante linguística do sertão, da zona da mata e do agreste de Alagoas, uma vez que o romance é ambientado nessa região. Em quase todos os parágrafos, depara-se o leitor com regionalismos.

$\mathrm{Na}$ tradução feita por Geneviève Leibrich, percebe-se uma tendência à utilização de recursos explicativos e uma mudança de registro: do coloquial, no texto "original", para mais formal na tradução, como podemos perceber nos exemplos abaixo:

[...] Il est des choses que je ne pourrais révéler en face, à qui que ce soit. Je les raconterai ici, parce que le livre sera publié sous un pseudonyme. Et si l'on venait à savoir que c'est moi l'auteur, nul doute qu'on me traiterait de bâbleur. (p. 11)

[...] Há fatos que eu não revelaria, cara a cara com ninguém. Vou narrá-los porque a obra será publicada com pseudônimo. E se souberem que o autor sou eu, naturalmente me chamarão potoqueiro. (p. 11)

Mesmo prevalecendo o tom formal, em alguns trechos notamos a tentativa do tradutor de manter uma linguagem mais simples, com a inserção de expressões coloquiais, aproximando a tradução do texto de partida, como podemos perceber no exemplo abaixo em que a tradutora modifica a estrutura do texto, para indicar a informalidade do discurso francês, visando a preservação do tom de oralidade que marca o desencadeamento do processo de instauração da escrita no texto de partida.

Je commence. Je m’appelle Paulo Honório, je pèse quatre-vingt-neuf kilos et j’ai en cinquante ans à la Saint-Pierre. (p. 14)

Começo declarando que me chamo Paulo Honório, peso oitenta e nove quilos e completei cinqüenta anos pelo São Pedro. (p. 15)

O texto é parcialmente redigido no pretérito perfeito, traço típico na literatura francesa e mais formal. Mesmo privilegiando o francês standard, a tradutora opta por inserir algumas palavras próprias de um contexto rural; palavras como 'savetier', 'hongreur' e 'clarine' são alguns dos exemplos:

Joaquim, le savetier, mourut. Germana tourna mal. (p. 16)

Joaquim sapateiro morreu. Germana arruinou. (p. 17) 
Comme un animal sous le couteau du hongreur (pour parler cru), je me débattis entre les griffes de Pereira, qui me saignait à blanc, le misérable. (p. 16)

De bicho de capação (falando com pouco ensino), esperneei nas unhas do Pereira, que me levou músculo e nervo, aquele malvado. (p. 17)

Para manter a couleur locale, proporcionando ao leitor um deslocamento para outra realidade, bem diferente da sua, a tradutora opta pela manutenção de algumas palavras em português como sertão, fazenda, contos e réis, sem qualquer nota explicativa, possivelmente por considerar que essas palavras podem ser compreendidas a partir do contexto:

Dans le sertão il passait des heures sans rien dire et, quand il était content, il chantait pour ses boufs. (p. 54)

No sertão passava horas calado, e quando estava satisfeito, aboiava. (p. 63)

[...] je lui prêtai deux contos qu'il s'empressa de dilapider aux cartes ainsi qu'en ripailles et en gnôle, avec des gueuses de bas étages, au Pain-sans-mie... (p. 18-19)

[...] emprestei-lhe dois contos de réis, que ele sapecou depressa na orelha da sota e em folias de bacalhau e aguardente, com fêmeas ratuínas, no Pão-semMiolo... (p. 21-22)

O vocábulo sertão, dicionarizado no final dos anos 70 , consta no dicionário como Zone peu peuplée et semi-aride du Nordeste brésilien, ou domine l'élevage extensif.

$\mathrm{Na}$ tradução de $S$. Bernardo, Geneviève Leibrich opta por não manter os nomes de plantas e animais em português. Quando não encontrado "equivalente" em francês, a tradutora opta por condensar o sentido ou explicar a palavra com o objetivo de suprir a ausência do vocabulário relativo à fauna e flora brasileira. Tais artifícios contornam, até certo ponto, o grau de estranhamento do texto em português.

Si l'biver prochain est comme celui-ci, tout est perdu: la terre se transforme en bourbier et il n'y vient plus même un pied de manioc.

Se o inverno vindouro for como este, desgraça-se tudo: isto vira lama e não nasce um pé de mandioca. (p. 37)

[...] et, alors que le docteur retournait sus ses terres, je lui tombai dessus sans crier gare. Je le ligotai et plongeai avec lui dans le maquis où je lui écorchai la couenne sur les chardons, les cactus et autres plantes à pointes et à épines. (p. 17)

[...] e quando o doutor ia para a fazenda, caí-lhe em cima de supetão. Amarrei-o, 
meti-me com ele na capoeira, estraguei-lhe os couros nos espinhos do mandacarus, quipás, alastrados e rabos-de-raposa. (p. 18)

No primeiro exemplo, constata-se a tradução do termo mandioca para o francês. No segundo, a tradutora utiliza o campo semântico cactus, para condensar o sentido dos diversos tipos de plantas presentes na região do sertão que não são conhecidas dos franceses e, possivelmente, cansariam a leitura. Como salientou Elizabeth Ramos (1999), os grupos sociais utilizam o que encontram disponível no seu meio ambiente e a partir disso geram valores e práticas culturais, que recebem nomes específicos, corroborando o posicionamento de Jakobson (1969, p. 69) de que "as línguas diferem essencialmente naquilo que devem expressar, e não naquilo que podem expressar".

Mais um exemplo dessa preferência por adaptar o texto à sua cultura aproximando-o do leitor alvo é a tradução de pirões por pains:

Au milieu de vos peines, la mort arrive, le diable vous emporte, vos amis font une mine longue d'une aune à votre enterrement, puis ils oublient jusqu'au pain qu'ils vous ont écorniflé. (p. 143)

No meio das canseiras a morte chega, o diabo carrega a gente, os amigos entortam o focinho na hora do enterro, depois esquecem até os pirões que filaram. (p. 176)

Percebem-se, também, algumas alterações de sentido, possivelmente, devido às características particulares a cada língua. A língua francesa não tem todas as tonalidades da língua portuguesa, obrigando os tradutores a buscarem soluções que, por vezes, amenizam o sentido da frase ou conotam imagens estereotipadas:

La nuit, tandis que les nègres se trémoussaient frénétiquement, empestant la sueur, soulevant dans le salon des nuages de poussière, que la musique des tambours et des fifres reprenait l'bymne national... (p. 19)

À noite, enquanto a negrada sambava, num forrobodó empestado, levantando poeira da sala e a música de zabumba e pífanos tocava o hino nacional... (p. 22)

Particularmente em S. Bernardo, Graciliano Ramos utiliza-se de inúmeras Unidades Fraseológicas (UFs) que dificultam a compreensão do leitor, ainda que falante do português. A dificuldade imposta ao tradutor é ainda maior e pode ser observada no exemplo a seguir:

[...] Au cours d'une veillé funèbre qui dégénera en kermesse, j’ai attrapai la Germana, une petite mulâtresse rousse qui avait le diable au corps, et je lui imprimai un méchant pinçon dans le gras de la fesse. Elle s'en compissa de plaisir. Mais ensuite elle me planta là pour s'en aller tournicoter autour 
de João Fagundes, un type qui changea de nom par la suite pour se faire voleur de chevaux. La conclusion, ce soir-là, fut que j’administrai à la Germana une bonne raclée et à João Fagundes un coup de couteau. Sur quoi le commissaire de police m'arrêta, je pris une volée de coups de trique et je me retrouvai à mijoter trois ans neuf mois et quinze jours sur la paille humide du cachot... (p. 15-16)

[...] Numa sentinela, que acabou em furdunço, abrequei a Germana, cabritinha sarará danadamente assanhada, e arrochei-lhe um beliscão retorcido na pôpa da bunda. Ela ficou se mijando de gosto. Depois botou os quartos de banda e enxeriu-se com o João Fagundes, um que mudou de nome para furtar cavalos. O resultado foi eu arrumar uns cocorotes na Germana e esfaquear o João Fagundes. Então o delegado de polícia me prendeu, levei uma surra de cipó-de-boi, tomei cabacinho e estive de molho, pubo, três anos, nove meses e quinze dias na cadeia... (p. 16)

Acreditamos que a tradução traz, inevitavelmente, as marcas do tradutor. E mesmo os tradutores ditos tradicionais refletem sua cultura, seu modo de pensar, de ser e de ver o mundo, que sempre afetarão sua interpretação do outro. Prova disso, encontramos nas escolhas feitas por Geneviève Leibrich: ela opta por adaptar o texto coloquial ao gosto francês, utilizando uma norma mais culta e amenizando expressões de caráter mais vulgar, utilizadas no texto em português, acrescentando outras na tentativa de deixar o texto mais francês. No exemplo acima, podemos citar a tradução da oração ela ficou se mijando de gosto por elle s'en compissa de plaisir.

Em relação à tradução das UFs, percebem-se três posicionamentos diferentes para a tradução. O primeiro posicionamento é o uso de expressões “equivalentes" em francês:

À chaque singe sa branche. (p. 95)

Cada macaco no seu galho. (p. 115)

Ailleurs qu'en ville je suis comme un poisson hors de l'eau. (p. 73)

Saindo daí, sou como peixe fora d'água. (p. 85)

A segunda postura é a explicitação da UF:

Et toi. Prendre une iniciative aussi dénuée de chance de succès en un moment pareil! (p. 51)

E você. Num momento como este dar murro em faca de ponta. (p. 59)

Vous dites toujours cela, bongonna Padilha. Mais vous avez du souffle, autant que sept chats réunis. (p. 94) 
- Sempre diz isso, resmungou Padilha. O senhor tem fôlego de sete gatos. (p. 114)

Por fim, a tradutora opta, em determinados momentos, pela tradução palavra por palavra talvez para manter uma imagem próxima daquela suscitada no texto em português:

Le perroquet mange le maïs et c'est la perruche qu'on accuse. Le perruche dans l'bistoire, c'est moi. (p. 141)

Papagaio come milho, periquito leva a fama. O periquito sou eu. (p. 172)

Seu Paulo a bon coeur et il est incapable de tuer un poussin. (p. 140)

Seu Paulo tem bom coração e é incapaz de matar um pinto. (p. 172)

Esses exemplos deixam patentes as dificuldades impostas à tradutora. De forma geral, Geneviève Leibrich faz uso de recursos explicativos facilitando a compreensão do texto traduzido. Sua estratégia principal é tornar o texto mais próximo de sua cultura. As diferenças de posicionamento da tradutora, quando diante de UFs, revelam sua visão de mundo e sua cultura. Percebe-se, no entanto, o recurso a alguns acréscimos na língua meta com o intuito de tornar o texto mais próximo da cultura alvo.

Não podemos, contudo, esquecer que, a tradução francesa passou por revisores e editores que, provavelmente, fizeram sugestões e modificações no texto traduzido. Não queremos, com essa afirmação, destituí-las de sua singularidade e autonomia, evidentemente. Nossa intenção é, meramente, pontuar que ela se manteve mais "presa" ao texto fonte, pois deveria "prestar contas" aos editores e à poética dominante da literatura francesa, no momento em que desempenhou sua tarefa. Mesmo tendo sua visão de mundo, suas escolhas próprias e estilo particular, a tradutora não teria tido autorização para "criar demais". Prova disso encontramos em uma carta escrita pela editora Gallimard, em abril de 1984, endereçada à Dona Heloísa Ramos, informando sobre o atraso na publicação de São Bernardo devido à necessidade de revisão para torná-la "completamente irrepreensível":

Examinamos atentamente a tradução francesa apresentada pela UNESCO da obra de Graciliano Ramos "São Bernardo". Acontece que, infelizmente, o texto francês não nos deixou satisfeitos e deve, necessariamente, ser retrabalhado pela tradutora. A publicação de nossa edição da obra será, portanto, adiada por alguns meses, mas a senhora compreenderá, acredito, que fazemos questão de que a versão francesa desse maravilhoso livro seja completamente irrepreensível ${ }^{12}$.

\footnotetext{
${ }^{12}$ Minha tradução de: «Nous avons examiné très attentivement la traduction française, présentée par l'UNESCO de l'cuvre de Graciliano Ramos 'São Bernardo'. Il s'avère hélas, que ce texte français ne nous donne pas satisfaction et qu'il doit nécessairement être retravaillé par la traductrice. La publication de notre édition de l'ouvrage se trouvera donc retardée de plusieurs mois, mais vous comprendrež, je pense, que nous tenions à ce que la version française de ce très beau livre soit tout à fait irréprochablè).
} 
A análise das marcas culturais revela a tentativa de Geneviève Leibrich, consciente ou não, de aproximar o texto do leitor francês, geograficamente distante do sertão de Alagoas. O processo de reescrita foi guiado não apenas pela tradutora, mas pelas exigências do polissistema francês, aqui representado pelos editores, revisores e, possivelmente, pelos críticos, que influenciaram diretamente na forma de tradução e na escolha da época em que os romances seriam traduzidos.

A diversidade entre as línguas e culturas envolvidas no ato tradutório e a certeza da existência de um sujeito recriador impedem a invisibilidade do tradutor e a consequente transparência do texto de chegada. A tradução será, portanto, sempre um trabalho singular de interpretação, no qual, o tradutor - ou os que exercem a patronagem ${ }^{13}$ - deve recriar um texto que será apenas uma entre as muitas possíveis leituras de um autor estrangeiro.

As traduções se caracterizam, portanto, como suplemento ${ }^{14}$, permitindo a sobrevivência do texto de partida em outra língua e garantem a leitores monolíngues o acesso ao que é escrito em outros lugares. A autonomia do processo tradutório dependerá, em grande parte, das autorizações e expectativas do polissistema alvo e de sua comunidade interpretativa, embora a tradução seja, evidentemente, uma atividade de criação, um gesto de reescritura, de interpretação e de reinvenção de um "original" impossível de ser analisada isoladamente.

\section{REFERÊNCIAS BIBLIOGRÁFICAS:}

BHABHA, Homi K. O local da cultura. Tradução de: Myriam Ávila, Eliana Lourenço de Lima Reis, Gláucia Renate Gonçalves. Belo Horizonte: UFMG, 1998.

BORGES, Ana Isabel; NERCOLINI, Marildo José. Tradução cultural: transcriação de si e do outro. Terceira Margem, Ano VII, n.8, 2003, p. 138-154.

DERRIDA, Jacques. “Carta a um amigo Japonês”. Tradução de: Érica Lima. In: OTTONI, Paulo (Org.). Tradução: a prática da diferença. Campinas: Editora da UNICAMP; FAPESP, 1998.

. "Lo Ilegible". In No escribo sin luz artificial. Cuatro, Ediciones - Valladolid, Espanha, 1999b, p. 49-64. Entrevista publicada pela primeira vez na Revista de Occidente número 62/63, 1986, p. 160-82.

HALL, Stuart. A identidade cultural na pós-modernidade. Tradução de: Tomaz Tadeu da Silva. Rio de Janeiro: DP\&A, 2006.

JAKOBSON, Roman. Linguística e comunicação. Tradução de Izidoro Blikstein e José Paulo Paes. São Paulo: Cultrix, 1969.

LEFEVERE, André. Translation/History/Culture. London and New York: Routledge, 1992b.

MAIA, Pedro Moacir. Cartas Inéditas de Graciliano Ramos a seus tradutores argentinos. Benjamin de Garay e Raúl Navarro. Salvador: EDUFBA, 2008.

PAES, José Paulo. Tradução a ponte necessária: aspectos e problemas da arte de traduzir. São Paulo: Ática, 2008.

\footnotetext{
${ }^{13}$ Termo cunhado por André Lefevere (1992b) para explicitar o poder de forças externas ao processo tradutório, tais como indivíduos e instituições (partidos políticos, editores, jornais, revistas, televisão, entre outros) que definem o que será lido ou deixará de ser, em termos de literatura.

${ }^{14}$ Termo cunhado por Derrida (1998). 
RAMOS, Graciliano. Cartas. 7a ed. Rio de Janeiro: Record, 1992. . S. Bernardo. 81 ${ }^{\mathrm{a}}$ ed. Rio de Janeiro: Record, 2005.

RAMOS, Elizabeth. Histórias de bichos em outras terras: a transculturação na tradução de Graciliano Ramos. Dissertação de mestrado. Programa de Pós-Graduação em Letras e Linguística da Universidade Federal da Bahia, 1999.

EVEN-ZOHAR, Itamar. Polysystem Theory. Poetics Today 1(1-2, Autumn), 1979, p. 287-310.

TORRES, Marie-Hélène Catherine. Variations sur l'étranger dans les lettres: cent ans de traductions françaises des lettres brésiliennes. Col. Traductologie. Lille : Artois Presses Université, 2004. 